\title{
Effect of Intracameral Dexamethasone Injection at Conclusion of Cataract Surgery on Macular Thickness in Diabetics
}

\author{
Amr Saad Bessa ${ }^{1^{*}}$, Tamer Mousa Ibrahim ${ }^{2}$ and Ahmed Mahmoud Ragab ${ }^{3}$ \\ 1,2,3 Ophthalmology Department, Faculty of Medicine, Alexandria University, Alexandria, Egypt
}

Received: 31 July, 2017; Accepted: 25 September, 2017; Published: 27 October, 2017

*Corresponding author: Amr Saad Bessa, Assistant professor of ophthalmology, Faculty of Medicine, Alexandria University, Alexandria, Egypt, Tel.: 002 034862506 and 002 01227991799; Email address: amrbessa@gmail.com

\begin{abstract}
Context: To measure central macular thickness (CMT) in diabetic patients after instilling intracameral dexamethasone at the end of cataract surgery and compare this measure with control group.

Design: Prospective case-control study.

Participants: 100 eyes of 100 diabetic patients undergoing cataract extraction.

Methods: 50 eyes received intracameral dexamethasone $0.4 \mathrm{mg} / 0.1 \mathrm{ml}$ at the end of surgery and 50 eyes received sham treatment as a control group. The CMT was measured before, one month, and three months after the surgery

Results: The mean CMT in was $261.32 \pm 9.45 \mu \mathrm{m}$ in the dexamethasone injected group while in the control group was 275.76 $\pm 21.36 \mu \mathrm{m}(\mathrm{p}<0.05)$ at the end of first month postoperatively. At the end of the third postoperative month the mean CMT was $262.34 \pm$ $10.77 \mu \mathrm{m}$ and $264.82 \pm 9.73 \mu \mathrm{m}$ in the dexamethasone injected group and the control group, respectively, $(p>0.05)$. The mean Intraocular Pressure (IOP) in the dexamethasone injected eyes was $14.98 \pm$ 2.82 and $15.1 \pm 2.82 \mathrm{mmHg}$ before and at the end of the first month following the surgery, respectively, ( $p>0.05)$.

Conclusion: The CMT of eyes which received intracameral dexamethasone is significantly lower than the control group at the end of first postoperative month, suggesting a possible role of intracameral dexamethasone in suppressing the early inflammatory response that can be linked to post cataract surgery macular edema in diabetics. A non significant increase in the IOP has been observed in the dexamethasone injected group this makes intracameral dexamethasone injection a possible safe practice at the end of cataract extraction in diabetics.
\end{abstract}

Keywords: Intracameral Dexamethasone; Cataract; Central Macular Thickness; Post- Cataract Macular Edema;

\section{Introduction}

Cataract formation and diabetic macular edema represent the main causes of visual loss among diabetic patients [1]. Cataract extraction in diabetics may be problematic as it could be complicated by either inducing macular edema or worsening of a preexisting one [2]. Thus, preventing and halting progression of macular edema is a paramount concern before deciding cataract surgery in diabetic patients. Many factors are responsible for macular edema formation following cataract surgery in diabetics with poor glycemic control and preexisting diabetic retinopathy being the most important causes [3]. Nevertheless, determining firm parameters to identify which eyes have the considerable risk remains unclear [4].

Several measures have been proposed to prevent macular edema occurrence following cataract extraction such as control of blood glucose level and topical administration of non steroidal inflammatory drugs [5].Surgical trauma induced inflammation is the main inducer of cystoid macular edema [6]. Several inflammatory mediators have been incriminated in pathogenesis of postsurgical macular edema like prostaglandins, cytokines and angiogenic growth factors [7].

Corticosteroid administration at the end of cataract surgery has been used by many surgeons to suppress surgically induced inflammation, subconjonctival injection being the most common practice [8]. Intracameral use of corticosteroid had been studied. There is evidence that the use of either intracameral dexamethasone or intracameral Triamcinolone Acetonide (TA) is equally effective in controlling postoperative inflammation after uneventful phacoemulsification [9].

The aim of the present study is to compare the central macular thickness in diabetic patients who received intracameral dexamethasone $0.4 \mathrm{mg} / 0.1 \mathrm{ml}$ at the end of cataract surgery to the central macular thickness in diabetic patients who received sham treatment at the conclusion of cataract extraction surgery.

\section{Methods}

The study was performed at Faculty of medicine, Alexandria University hospital, between November 2016 through April 2017, Alexandria, Egypt. The study adhered to the tenets of the Declaration of Helsinki. Institutional Review Board (IRB)/ethics committee approval for human studies has been obtained.

Patients with visually significant cataract undergoing cataract surgery were eligible for enrollment. Visually significant cataract was defined by: any LOCS II grading $\geq 2$ using the slit lamp-based Lens Opacities Classification System II (LOCS 
II), BCVA $<20 / 40$, cataract as the primary cause of vision impairment and self-reported vision of fair or worse. Diabetic patients previously emmetropic with good glycemic control as indicated by hemoglobin A1c level were included in the study. Patients with any degree of retinopathy or history of diabetic macular edema, $\mathrm{Hb}$ A1c more than $7 \%$, patients with type 1 DM, duration of diabetes more than 5 years and less than 3 years were excluded. Patients who had other ocular pathologies, such as uveitis, previous trauma, previาous ocular intervention, glaucoma, current use of oral or topical anti-inflammatory agents (steroidal or non-steroidal), history of steroid responsiveness, pigment dispersion syndrome, pseudo exfoliation syndrome, age-related macular degeneration, any retinopathy, a history of cystoid macular edema, were also excluded from the study.

One hundred eyes of 100 patients underwent elective uneventful phacoemulsification and foldable intraocular lens implantations were enrolled in this case control prospective study. All patients were informed about the design of the study and the procedure involved, and all gave written informed consent. A complete patient's evaluation was performed, which included the patient's age, medical and ocular history. A detailed preoperative ophthalmic evaluation including slit-lamp examination, Intraocular Pressure (IOP) measurement with Goldman applanation tonometry, central corneal thickness measurement with ultrasonic pachymetry and dilated fundus examination was performed in addition to measuring Central Macular Thickness (CMT) with Spectral Domain Optical Coherence Tomography (SD-OCT) using the Cirrus HD-OCT (Carl Zeiss Meditec, Dublin, CA) and scans were acquired using the Macular Cube $512 \mathrm{x}$ 128, Enhanced HD Raster, and HD 5 Line Raster protocols. All operations were performed by the same surgeon (AB) under topical anesthesia. Dilating drops in the form of phenylephrine $2.5 \%$ and tropicamide $1 \%$ eye drops were instilled before surgery. After topical anesthesia, a $2.8 \mathrm{~mm}$ clear corneal incision was made, after which sodium chondroitin sulphate $4 \%$-sodium hyaluronate 2\% (Viscoat, Alcon, Pharmaceuticals Ltd) was injected and capsulorhexis was performed. The surgeon performed standard phacoemulsification using the phaco-chop technique (mean phaco time was $9.2 \pm 1.3$ seconds and the mean operation time was $8 \pm 2.4$ minutes). The capsular bag was expanded with sodium hyaluronate 1\% (Healon, Abbott Medical Optics), and a foldable acrylic intraocular lens was implanted in the capsular bag. The viscoelastic substance was removed vigorously from the bag, the capsular fornix, and the anterior chamber in a standard fashion using an irrigation/aspiration system.

At the end of the surgery, patients were randomly allocated to one of two groups. In group 1 ( $\mathrm{n}=50$ eyes of 50 patients), dexamethasone $0.4 \mathrm{mg} / 0.1 \mathrm{ml}$ was injected into the anterior chamber through a paracentesis using a 27-gauge cannula. In group 2 ( $\mathrm{n}=50$ eyes of 50 patients), sham injection was performed. The surgeon did not know which drug was being injected either the sham or dexamethasone. Immediately after surgery, moxifloxacin $0.5 \%$ eye drop was prescribed five times a day for 1 week, and prednisolone acetate 1\% eye drop were prescribed five times a day with a one drop/week taper over five weeks.

Patients were examined on the postoperative days 1,7 , 30 and 90. Postoperative evaluations included patient history regarding any ocular complain, Snellen Visual Acuity (VA), slitlamp examination, IOP measurement and fundus examinations. Evaluation was based on central macular thickness measurement before and on 30 and 90 postoperative days. Central Macular Thickness (CMT) analysis was done by independent observer.

The preoperative IOP was measured using a Goldmann applanation tonometry, 1 day before surgery. The postoperative IOP was measured using the same Goldmann applanation tonometry 1 day, 7 day, and 30 days after surgery.

Statistical analysis was performed using SPSS software (Statistical Package for the Social Sciences, version 9.0, SPSS Inc., Chicago, III, USA). Central Macular Thickness (CMT) measurements were compared in each group at baseline, on 30 day and 90 days postoperatively using $\mathrm{F}$ test (ANOVA) with repeated measures, while Student t-test was used for comparing between the two studied groups in the studied periods. A P $\leq$ 0.05 was considered statistically significant. Mean IOP changes in dexamethasone injected group before the surgery and on postoperative day 30 were compared using Paired t-test.

\section{Results}

Patients in group 1 included 23 women and 27 men with mean age $50 \pm 7.3$ years. Group 2 included 25 women and 25 men with an average age of $53.4 \pm 5.2$ years. The mean $\mathrm{Hb} \mathrm{A1c}$ at the end of third postoperative month among group 1 patients was $6 \pm 0.20 \%$ while in the other group it was $6 \pm 0.23 \%$. There were no significant differences between the groups as regard age, gender and $\mathrm{Hb}$ A1c level $(\mathrm{P}>0.05)$. There were no intraoperative or postoperative complications in any eye.

The CMT was measured with the aid of Spectral Domain Optical Coherence Tomography (SD-OCT) using the Cirrus HDOCT (Carl Zeiss Meditec, Dublin, CA) and scans were acquired using the Macular Cube 512 x 128, Enhanced HD Raster, and HD 5 Line Raster protocols. The mean CMT in group 1 was $260.30 \pm$ $7.62 \mu \mathrm{m}$ and in group 2 was $262.54 \pm 5.81 \mu \mathrm{m}$ before the surgery ( $\mathrm{p}>0.05$ ). On the 30 day postoperatively, group 1 CMT was $261.32 \pm 9.45 \mu \mathrm{m}$ and $262.34 \pm 10.77 \mu \mathrm{m}$ on the 90 postoperative day, while in group 2 CMT was $275.76 \pm 21.36 \mu \mathrm{m}$ and $264.82 \pm$ $9.73 \mu \mathrm{m}$ on the 30 and 90 postoperative days, respectively. The difference in CMT between the two studied group was statistically significant ( $\mathrm{p} \leq 0.05$ ) on 30 postoperative day. Interestingly, both groups showed a non significant increase in CMT in the studied follow up periods as compared to baseline values. (Table 1)

The intraocular pressure (IOP) was measured with Goldman applanation tonometry. Group 1 eyes showed non-significant increase in IOP. The mean IOP at baseline in this group was 14.98 $\pm 2.82 \mathrm{mmHg}$ which increased to $15.1 \pm 2.82 \mathrm{mmHg}$ by the end of the 30 postoperative day. (Table 2) 
Table 1: Comparison between the CMT in $\boldsymbol{\mu m}$ during different periods of the study in the two studied groups

\begin{tabular}{|c|c|c|c|}
\multirow{2}{*}{ CMT } & \multirow{4}{*}{ Baseline } & \multicolumn{2}{|c|}{ After injection } \\
\cline { 2 - 4 } & & 1 month & 3 months \\
\hline Min. - Max. & $245.0-277.0$ & $246.0-280.0$ & $240.0-294.0$ \\
\hline Mean \pm SD. & $260.30 \pm 7.62$ & $261.32 \pm 9.45$ & $262.34 \pm 10.77$ \\
\hline Median & 260 & 258.5 & 259 \\
\hline P & \multicolumn{3}{|c|}{$\mathrm{p} 1=0.505, \mathrm{p} 2=0.249, \mathrm{p} 3=0.420$} \\
\hline \multicolumn{3}{|c|}{ Group II (n=50) } \\
\hline Min. - Max. & $253.0-274.0$ & $253.0-323.0$ & $253.0-297.0$ \\
\hline Mean \pm SD. & $262.54 \pm 5.81$ & $275.76 \pm 21.36$ & $264.82 \pm 9.73$ \\
\hline Median & 261 & 280.5 & 265.5 \\
\hline P & \multicolumn{3}{|c|}{$\mathrm{p} 1<0.001^{*}, \mathrm{p} 2=0.102, \mathrm{p} 3=0.001^{*}$} \\
\hline t (p) & $1.653(0.101)$ & $2.213^{*}(0.029 *)$ & $0.959(0.340)$ \\
\hline
\end{tabular}

CMT: central macular thickness

$\mathrm{p}$ : $\mathrm{p}$-value for $\mathrm{F}$ test (ANOVA) with repeated measures for comparing between different periods in each group.

$\mathrm{t}, \mathrm{p}$ : $\mathrm{t}$ and $\mathrm{p}$ values for Student $\mathrm{t}$-test for comparing between the two studied groups

p1: p-value for comparing between Baseline and after injection 1 month

p2: p-value for comparing between Baseline and after injection 3 month

p3: p-value for comparing between 1 month after injection and 3 months after injection

*: Statistically significant at $\mathrm{p} \leq 0.05$

Table 2: Comparison between the IOP at the base line and after 1 month in dexamethasone injected group Group I $(n=50)$

\begin{tabular}{|c|c|c|}
\hline IOP & Baseline & 1 Month After Injection \\
\hline Min. - Max. & $10.0-22.0$ & $10.0-22.0$ \\
\hline Mean \pm SD. & $14.98 \pm 2.82$ & $15.1 \pm 2.82$ \\
\hline Median & 15 & 15 \\
\hline p & 0.083 & \\
\hline
\end{tabular}

$\mathrm{p}$ : $\mathrm{p}$-value for Paired t-test for comparison between baseline and 1 month after injection.

\section{Discussion}

Intracameral dexamethasone injection appears to be effective safe practice to be adopted in any diabetic patient undergoing cataract surgery. Surgical trauma associated with cataract extraction can trigger inflammatory cascade inside the eye with resulting anterior chamber reaction, high intraocular pressure, corneal edema and cystoid macular edema with resultant slow visual recovery and poor patient satisfaction [10]. Although the breakthrough technology in phacoemulsification and IOL designs has significantly reduced the ocular inflammatory response to cataract extraction, ocular inflammation after cataract surgery remains a concern. Several studies have studied the role of intracameral steroids in reducing ocular inflammatory response to cataract surgery $[11,12]$. Also, intravitreal dexamethasone has long been proven to be effective in treatment of diabetic macular edema [13]. Chang DT et al. have been studied the role of intracameral dexamethasone in decreasing ocular inflammatory response in glaucomatous and non-glaucomatous eyes. They found that anterior chamber reaction was significantly reduced in the eyes which received intracameral dexamethasone without any concern regarding IOP elevation whether these eyes were glaucomatous or not [11]. In this current study it was demonstrated that intracameral dexamethasone injection at the conclusion of cataract surgery had a significant effect on CMT. Also, this effect was demonstrated in previous studies when dexamethasone is given through intravitreal route and this may be attributed to its strong anti-inflammatory properties $[14,15]$.

Intracameral dexamethasone anti-inflammatory effect at the end of phacomulsification has been studied and this effect may be the cause of suppressing edema formation in the dexamethasone injected group in this study [9]. Safety concerns over the IOP elevation do not seem to be an issue. The current study showed that there was non-significant elevation of IOP at the end of first operative month. This agrees with Chang et al. and Güngör SG et al. who demonstrated that dexamethasone intracamerally does not carry a significant risk of increase in IOP $[9,11]$

The current study has some limitations. While intravitreal dexamethasone has a therapeutic level, the intracameral route of administration remains questionable to reach this level. In addition, although many factors have been standardized to eliminate possible confounding factors, the use of topical steroid postoperatively by the patients and whether patients were complaint or not might have some possible effect on CMT.

\section{Conclusion}

In conclusion, CMT was significantly higher in eyes which received intracameral sham injection compared to intracameral dexamethasone injected eyes. Intraocular pressure in the dexamethasone injected group showed non-significant increase. Thus, intracameral dexamethasone $0.4 \mathrm{mg} / 0.1 \mathrm{ml}$ could play an important role in suppressing the inflammatory response resulting from surgical trauma and consequently preventing macular edema formation after uncomplicated cataract surgery in type 2 diabetic patients with no concerns over inducing any increase in IOP.

\section{References}

1. Klein BE, Klein R, Moss SE. Incidence of cataract surgery in the Wisconsin Epidemiologic Study of Diabetic Retinopathy. Am J Ophthalmol. 1995;119(3):295-300.

2. Baskin DE. Optical coherence tomography in diabetic macular edema. Curr Opin Ophthalmol. 2010;21(3):172-177. doi: 10.1097/ ICU.0b013e32833866ae 
3. Baker CW, Almukhtar T, Bressler NM, Glassman AR, Grover S, Kim SJ, et al. Macular edema after cataract surgery in eyes without preoperative central-involved diabetic macular edema. JAMA Ophthalmol. 2013;131(7):870-879. doi: 10.1001/ jamaophthalmol.2013.2313

4. Arevalo JF. Diabetic macular edema: changing treatment paradigms. Curr Opin Ophthalmol. 2014; 25(6):502-507. doi: 10.1097/ ICU.0000000000000102

5. Yavas GF, Ozturk F, Kusbeci T. Preoperative topical indomethacin to prevent pseudophakic cystoid macular edema. J Cataract Refract Surg. 2007;33:804-7. doi: 10.1016/j.jcrs.2007.01.033

6. Dick HB, Schwenn O, Krummenauer F, KristR,Pfeiffer N. Inflammation after sclerocorneal versus clear corneal tunnel phacoemulsification Ophthalmology. 1999;107:241-247.

7. Murata T, Nakagawa K, Khalil A, Ishibashi T, Inomata H, Sueishi K The relation between expression of vascular endothelial growth factor and breakdown of the blood-retinal barrier in diabetic rat retinas. Lab Invest 1996;74:819-825.

8. Dieleman M, Wubbels RJ, van Kooten-Noordzij M, de Waard PW. Single perioperative subconjunctival steroid depot versus postoperative steroid eyedrops to prevent intraocular inflammation and macular edema after cataract surgery. J Cataract Refract Surg. 2011;37(9):1589-1597. doi: 10.1016/j.jcrs.2011.03.049

9. Güngör SG, Bulam B, Akman A, Colak M. Comparison of intracameral dexamethasone and intracameral triamcinolone acetonide injection at the end of phacoemulsification surgery. Indian Journal of Ophthalmology. 2014;62(8):861-864. doi: 10.4103/03014738.141045
10. Rowen S. Preoperative and postoperative medications used for cataract surgery. Curr Opin Ophthalmol. 1999;10(1):29-35.

11. Chang DT, Herceg MC, Bilonick RA, Camejo L, Schuman JS, Noecker $\mathrm{RJ}$. Intracameral dexamethasone reduces inflammation on the first postoperative day after cataract surgery in eyes with and without glaucoma. Clin Ophthalmol. 2009;3:345-355

12. Karalezli A, Borazan M, Akova YA. Intracameral triamcinolone acetonide to control postoperative inflammation following cataract surgery with phacoemulsification. Acta Ophthalmol. 2008;86(2):183-187. doi: 10.1111/j.1600-0420.2007.01114.x

13. Martidis A, Duker JS, Greenberg PB, Rogers AH, Puliafito CA, Reichel E. Intravitreal triamcinolone for refractory diabetic macular edema. Ophthalmology. 2002;109(5):920-927.

14. Haller JA, Kuppermann BD, Blumenkranz MS, et al. Dexamethasone DDS Phase II Study Group randomized controlled trial of an intravitreous dexamethasone drug delivery system in patients with diabetic macular edema. Arch Ophthalmol. 2010;128:289-96.

15. Meyer CH, Klein A, Alten F, Liu Z, Stanzel BV, Helb HM, et al. Release and velocity of micronized dexamethasone implants with an intravitreal drug delivery system: kinematic analysis with a highspeed camera. Retina. 2012;32(10):2133-2140. doi: 10.1097/ IAE.0b013e31825699e5 